The University of Southern Mississippi

The Aquila Digital Community

Faculty Publications

$1-1-2019$

\title{
An Army of One: Predaceous Diving Beetle Life History Stages Affect Interactions With Shared Mosquito Prey
}

Carmen E. Bofill

University of Southern Mississippi

Donald A. Yee

University of Southern Mississippi, donald.yee@usm.edu

Follow this and additional works at: https://aquila.usm.edu/fac_pubs

Part of the Entomology Commons

\section{Recommended Citation}

Bofill, C. E., Yee, D. A. (2019). An Army of One: Predaceous Diving Beetle Life History Stages Affect Interactions With Shared Mosquito Prey. Hydrobiologia, 827(1), 201-209.

Available at: https://aquila.usm.edu/fac_pubs/15547

This Article is brought to you for free and open access by The Aquila Digital Community. It has been accepted for inclusion in Faculty Publications by an authorized administrator of The Aquila Digital Community. For more information, please contact Joshua.Cromwell@usm.edu. 
1 An army of one. Predaceous diving beetle life history stages affect interactions with shared

2 mosquito prey

3

4

5 C. Bofill ${ }^{1,3}$ and D.A Yee ${ }^{1,2}$

6

$7 \quad{ }^{1}$ Department of Biological Sciences, University of Southern Mississippi, Hattiesburg,

8 Mississippi, 39460, U.S.A., 601-266-4927

$9 \quad{ }^{2}$ Author of correspondence: donald.yee@usm.edu

10 3Present address: Vanderbilt University Medical Center, 719 Thompson Lane, Suite 57182,

11 Nashville, TN 37204

12

13 Short title: Complex life-history effects of predators on prey

14

15

16

17

18

19

20

21

22

23 


\section{Abstract}

25 Predators with complex life cycles often differ in their morphology, behavior, and trophic

26 position across their ontogeny, and may thus have variable effects on shared prey. We used the

27 predaceous diving beetle Laccophilus fasciatus rufus as our predator, whose larvae and adults

28 often co-occur in freshwater lentic systems. As a shared prey we used early and late instar Culex

29 quinquefasciatus, a common wetland mosquito. We found that single adult predators were more

30 likely to consume late instar prey compared to juvenile predators, who ate early and late instar

31 prey equally. A mixture of juvenile and adult predator stages led to higher consumption of prey

32 when compared to either predator type alone. Adult dytiscids consumed three times as many

33 dead prey compared to living ones, thus implying a role in scavenging for this life history stage.

34 Our work highlights that predators with complex life history stages may affect shared prey in 35 complicated and unpredictable ways.

37 Keywords: complex life cycle, Culicidae, Dytiscidae, pond 
Temporary lentic aquatic systems are often dominated by animals that exhibit complex life

48 cycles, including anurans and many insects, however the interactions of these adult and juvenile

49 predators with other species are not well studied. A complex life cycle is a maturation cycle in

50 which different morphological changes occur during the growth of an organism (Wilbur 1980).

51 Examples of animals that have a complex life cycle amphibians (e.g., frogs), many marine

52 invertebrates, and many aquatic insects (e.g., Odonata, Coleoptera). Some insects exhibit indirect

53 metamorphosis, wherein adults and juveniles are morphologically distinct, as opposed to direct

54 metamorphosis where the emerging young are just smaller versions of the adults. Besides

55 morphological changes, some animals with complex life cycles have larval and adult stages that

56 occur in different habitats, have different diets, and are exposed to different interactions

57 (predation, mutualisms) (Wilbur 1980). Predators with complex life cycles may exert different

58 effects on a food web depending on their stage, and their effects may move beyond their current

59 niche (McCoy et al. 2009).

60 Although common in lentic habitats, predaceous diving beetles (Coleoptera: Dytiscidae),

61 have received little attention as predators. What is known is that they are important predators on

62 both invertebrate and vertebrate prey (Culler et al. 2014). This highly diverse family of predators

$63(\sim 4,200$ species worldwide) play a structurally important role in aquatic food webs (Thakare \&

64 Zade 2011) and are potentially important predators of many taxa, including mosquito larvae, in

65 natural habitats (Larson et al. 2000), especially in fishless systems (Batzer \& Wissinger 1996).

66 Adult dytiscids are often capable of flight and move among isolated bodies of freshwater, using

67 vision, chemoreception, and vibration to recognize and choose their prey (Hagen et al. 1976).

68 When comparing them to their juvenile counterparts, whom are obligate aquatic predators

69 requiring prey movement to elicit a response, adult dytiscids are not adept hunters (Johnson et al. 
70 2003). Unlike adults, juveniles have also been seen to exhibit a variety of different predatory

71 behaviors including sit-and-pursue, sit-and-wait, and active hunting modes (Young 1967,

72 Formanowicz 1982, Yee 2010). Regarded as "clumsy", the adults may select prey that is easy to

73 capture, including dead or dying individuals; scavenging on dead material that may be

74 energetically favorable (Bosi 2001). Adults and juvenile beetles often co-occur in the same

75 habitats (Larson et al. 2000), however it is unknown how the different stages within each species

76 differ with respect to predation.

77 Mosquito larvae are thought to be an important food item for many aquatic animals,

78 including many species of predaceous diving beetles (summarized in Culler et al. 2014, Shallan

79 \& Canyon 2009). Since the 1990s, insecticides have become a widely acceptable method of

80 mosquito control, but resistance to these chemicals have been a challenge to effective control

81 measures (Brogdon \& McAllister 1998). As a consequence of this resistance, aquatic ecologists

82 see the necessity to study the use of natural predators as a biocontrol on mosquito populations.

83 Research on larval mosquito population control via aquatic predators has become of recent

84 interest, however the focus on these investigations has been on factors like prey stage (Chandra

85 et al. 2008), habitat characteristics (Ohba \& Ushio 2015), and prey type (Culler \& Lamp 2009).

86 Currently, no studies have investigated the effects of different predator life-history stages on

87 consumption of mosquito prey.

88 We conducted a series of experiments to better understand the contribution of both the adults

89 and juveniles of the beetle Laccophilus fasciatus rufus on prey populations of the mosquito

90 Culex quinquefasciatus. Laccophilus fasciatus rufus is a common dytiscid in North America

91 (Larson et al. 2000) and has been shown to prey on mosquitoes (Pitcher \& Yee 2014). Culex

92 quinquefasciatus (southern house mosquito) is a common open water mosquito that has a world- 
93 wide distribution, and has been used as a prey species of dytiscid predation elsewhere (Aditya et

94 al. 2006, Chandra et al. 2008). Specifically, our objectives in this study were to 1) quantify

95 consumption rates of $L$. f. rufus adults and juveniles on different stages of mosquito larvae under

96 different prey and plant densities, 2) examine if combinations of predator life-history stages

97 affected predation rates compared to single predator stages, and 3) test adult dytiscid prey

98 preference between living and dead prey. We hypothesized that because of potential differences

99 in hunting behavior and other life-history differences (Yee 2010), adult and juvenile predators

100 will display different effects on prey populations. For instance, as adults are more likely to

101 exhibit searching behavior (Larson et al. 2010) and some juveniles are known to be sit-and-wait

102 hunters (Yee 2010), we may predict that adults would consume more prey given the potential for

103 higher encounter rates, and that these differences may also influence predation rates in single

104 versus multi-predator trials. Studying such interactions will improve the understanding of the

105 effect of the complex life history of predators on shared prey in general, and will lead

106 specifically to a better understanding of the bio-control abilities of dytiscids in natural

107 environments.

108

109 Materials and Methods

110 Laccophilus fasciatus rufus. No taxonomic keys exist to distinguish different species of

111 Laccophilus larvae (hereafter, juveniles, to distinguish from mosquito prey). Thus, to assure that

112 the correct species of Laccophilus was used, breeding of adults in a controlled setting was

113 necessary. Specifically, adult L.f. rufus were collected from aquatic habitats in and around

114 Hattiesburg, MS ( $\left.31^{\circ} 19^{\prime} 38^{\prime \prime} \mathrm{N}, 89^{\circ} 17^{\prime} 25^{\prime \prime} \mathrm{W}\right)$. Males and females were placed in large plastic

115 tubs $(91.5 \times 61 \times 20.3 \mathrm{~cm})$ containing aquatic plants, pond water, food, and substrate. Plants 
116 (Ludwigia palustris) were collected from ponds locally and rinsed repeatedly to remove

117 invertebrates. Tubs were covered with no-see-um mesh and left for several weeks at the USM

118 Science Park, located approximately $8 \mathrm{~km}$ east of the Hattiesburg campus, during which time any

119 juveniles that were produced were removed for experiments (genus level identifications were

120 made using Larson et al. 2000). For experiments requiring adults, additional L.f. rufus were

121 collected from aquatic habitats and isolated in separate plastic cups containing $100 \mathrm{~mL}$ filtered

122 pond water and a wooden perch. Adults and juveniles were fed once daily using frozen

123 chironomid larvae or live mosquitoes until experimental trials began. All juveniles used in the

124 experiments were either $2^{\text {nd }}$ or $3^{\text {rd }}$ instars. Predation by either adults or juvenile predator stages

125 were easily distinguishable based on known behavior: mosquitoes killed by adults were wholly

126 consumed or dismembered, whereas juveniles pierce and suck prey leaving only an empty

127 exoskeleton. Prey (Culex quinquefasciatus) were obtained from laboratory colonies ( $\mathrm{F}_{4}$ or less)

128 that were originally collected as egg rafts from areas near campus.

129 Experiment 1. Predator stage and consumption of different prey stages. To quantify

130 predation rates on shared mosquito prey, both juvenile and adult beetles were used separately in

131 feeding trials. Feeding trials were conducted in small plastic aquaria $(20.3 \times 15.2 \times 12.7 \mathrm{~cm})$

132 filled with 3.9 L filtered pond water collected from ponds in the study area. In each aquarium,

133 three different levels of plant stem density were used: 0, 3, and 6 stems (hereafter no, low, and

134 high plant densities). We used Ludwigia palustris, a plant that is commonly found in dytiscid

135 habitats in the study area at variable densities (Pitcher \& Yee 2014). Testing predation on

136 mosquitoes under different plant densities has been shown to affect predator-prey interactions

137 (Savino \& Stein 2011, Yee, 2010) and we predicted that increasing plant density would increase

138 refugia for prey and thus reduce predation rates. Prey density trials consisted of three levels: 5, 
13910 , or 15 of either early $\left(1^{\text {st }}\right.$ and $\left.2^{\text {nd }}\right)$ or late $\left(3^{\text {rd }}\right.$ and $\left.4^{\text {th }}\right)$ instar Culex quinquefasciatus, hereafter

140 low, medium, and high prey. In some lentic systems different levels of mosquito prey can also

141 affect predation rates (Alto et al. 2012). Culex quinquefasciatus is often found in open water

142 (Vinogradova 2000) and often cohabitates with these predators (unpublished data). Inclusion of

143 different sized prey let us examine how predator life stages affect predation across prey life

144 history stages. Plant density (3), prey density (3), and prey stage (2) were crossed to yield 18

145 combinations that were replicated 5 times for each predator stage. Uneaten mosquitoes were

146 counted after $4 \mathrm{hrs}$ in each aquarium. Aquariums were placed in an incubator at $27^{\circ} \mathrm{C}$ on a $14: 10$

147 (dark:light) photoperiod (approximate summer conditions for the study area).

148 To assess differences in prey consumption a four-way analysis of variance (ANOVA) was

149 used to determine if differences existed among the different plant densities (3), prey densities (3),

150 prey stages (2), and predator stage (2). A $\log _{(x+1)}$ transformation was applied to the raw data to

151 meet assumptions of normality. Tukey's test were then conducted to assess differences among

152 specific treatment levels while controlling for experimental-wise error rates. All statistical

153 analyses were conducted in SAS (SAS 2004).

154 Experiment 2. Single and multiple predator stages and prey consumption. We examined

155 how single and mixed predator life history stages affected consumption of early and late instar

156 prey. Specifically, we placed either two adult predators, two juveniles, or one of each into

157 aquaria established in the same manner as described above, with 10 prey of each stage offered in

158 the single prey treatment levels and 10 of each in the combined level. For these trials, beetles

159 were starved $24 \mathrm{hrs}$ prior to introducing them into aquaria to standardize hunger levels; trials ran

160 for four hours. We discarded one replicate of the mixed predator treatment level from analysis as

161 the adult beetle killed the juvenile. We also prepared 6 replicates of two juveniles and a juvenile 
162 and adult predator without prey to evaluate potential predation among predators (we assumed

163 that adults were unlikely to kill one another) and three replicates with no predators (control) and

164 collected data as above.

165 A two-way ANOVA was used to assess differences in consumption of different prey stages

166 (early, late) across predator combinations (juvenile alone, adult alone, juvenile and adult). Raw

167 data met assumptions and differences among levels of significant treatment effects were assessed

168 using a Tukey adjustment.

169 Experiment 3. Adult predator selection of prey. Experiment 1 did not produce differences in

170 predation rates among prey densities or plant densities (see Results). These treatments were

171 subsequently excluded from this study, and we used three sprigs of plant for all replicates.

172 Furthermore, only late instar prey were utilized as adult dytiscids were observed to consume

173 significantly more late compared to early instar mosquito larvae. Specifically, we used three

174 different prey treatment levels to examine prey preference for adult beetles only: 10 dead

175 mosquito larvae, 10 living larvae, and 5 dead and 5 living. Larvae were freshly killed by placing

176 them in water in a microwave for approximately 1 minute. Each treatment level was replicated

177 six times yielding 24 experimental units. All other aspects of this experiment (e.g., aquarium

178 size, time until data collected) were the same as the ones described above.

179 A one-way ANOVA was used to test for differences between different prey treatment levels

180 (percent of prey eaten by adult dytiscids in the living, dead, of the combination of living and

181 dead treatment levels). Raw data met assumptions of the analysis.

182 Results

183 Experiment 1. Predator stage and consumption of different prey stages. We detected

184 significant effects of predator stage and a prey stage by predator stage interaction; other effects 
185 were not significant (Table 1). Specifically, adult beetles consumed more late instar mosquitoes

186 compared to juvenile beetles, whereas both predator stages consumed a similar but lower number

187 of early instar mosquitoes (Fig. 1).

188 Experiment 2. Single and multiple predators stages and prey consumption. No prey died in

189 the no predator controls, however in two replicates of the controls without prey juveniles were

190 killed by adults (33\%). About 30\% more prey were consumed when an adult and juvenile were

191 together than when either stage was alone $($ Fig. $2 \mathrm{~A})\left(\mathrm{F}_{2,46}=6.01, \mathrm{P}=0.005\right)$. The highest

192 consumption was on early instar prey offered alone, followed by either early instars in

193 combination with late instars or late instars by themselves (Fig. 2B) $\left(\mathrm{F}_{3,46}=31.51, \mathrm{P}<0.001\right)$.

194 Late instar prey offered with the early stage were consumed least overall (Fig. 2B). The

195 interaction between predator combination and prey combination was not significant $\left(\mathrm{F}_{6,46}=1.99\right.$,

$196 \mathrm{P}=0.087)$.

197 Experiment 3. Adult predator selection of prey. Adults ate three times as many dead prey

198 compared to living prey when both types were offered simultaneously (Fig. 3) $\left(\mathrm{F}_{3,16}=5.944, \mathrm{P}=\right.$

199 0.007). In addition, the overall consumption of live or dead prey did not vary when these types

200 were offered alone or in combination, indicating that prey density did not affect prey selection.

202 Discussion

203 It has been assumed that predators species are interchangeable in their effects on prey

204 (Fretwell 1987), however such an assumption is likely wrong, given that different predators may

205 act in dissimilar ways to enhance or weaker overall predation pressure in food webs (Schmitz

206 2007). However, little attention has been paid to predators with complex life cycles, wherein

207 different life history stages may exert different forces on shared prey. Our goal was to test for 
208 consumption differences for adults and juveniles of L.f. rufus on a shared prey, which would

209 allow us to examine the specific nature of predation effects of a predator with a complex life

210 cycle on a shared prey. Our hypothesis that adult and juvenile predators would display different

211 effects on prey populations was generally supported. We found that adult $L$. f. rufus consumed

212 more late instar mosquito larvae compared to juveniles; adults also consumed more dead than

213 living prey. The higher consumption of larger prey by adult predators may be due to energetic

214 differences, as larger prey are likely an easier target for adults compared to juvenile predators

215 and have a higher caloric value. Adult beetles are fast-moving adept swimmers, whereas larvae

216 generally walk along the bottom or on surfaces and often sit and wait for prey, and thus capture

217 of larger prey is likely easier for adults compared to juveniles. However, we found no differences

218 in predation on early instars, suggesting that both juveniles and adults can equally affect small

219 mosquitoes. Although we found no significant differences between prey sizes within each

220 predator stage consumption of early and late instars for adult predators did approach significance

$221(\mathrm{P}=0.084)$, whereas juveniles did not $(\mathrm{P}=0.180)$. This would seem to bolster the possibility that

222 the larger, more active adult predators are more adept in consuming larger versus smaller prey.

223 At present, no other study has compared predator consumption for different dytiscid life history

224 stages across prey sizes within a prey species. Aditya and Saha (2006) did find that feeding rates

225 of adult Rhantus sikkimensis were higher on small chironomid prey versus larger ones, a finding

226 that is opposite of ours. Moreover, Lundkvist et al. (2003) found differences in mosquito size

227 preferences for three species of dytiscids, and concluded that there should exist an inverse

228 relationship between predator size and prey size, a prediction our data does not support.

229 The differences between consumption by beetles for a single prey type in our study are

230 broadly consistent with work by Klecka and Boukal (2012) who showed that adult and juvenile 
231 dytiscids (Acilius sp.) exhibited preferences for different prey, with juveniles preferring Culex sp.

232 and adult beetles preferring chironomids. This could be explained by differences in prey

233 movement and location. Because of a lack of refugia, chironomids were an easy target for

234 predators, and likely required low effort by adults to obtain them (Klecka and Boukal 2012).

235 Regardless of the mechanism, such ontogenetic diet shifts (ODS) might be expected as a way to

236 reduce intraspecific competition, and would also be predicted when animals change in

237 morphology, size, and behavior over their life cycle (Ohba 2009, Klecka \& Boukal 2012). Such

238 shifts may not always be perfect, allowing a degree of overlap that would bring adults and

239 juveniles into direct competition. Indeed, Klecka and Boukal (2012) did show that diet overlap

240 was pronounced for life history stages in two species of dytiscids, but did not offer any

241 mechanism for how species may limit intraspecific competition. Instead of dampening

242 competition, we suggest that with greater diet overlap there may be more opportunities for

243 predation among the predators (i.e., intraguild predation (IGP)). We found some evidence for

244 IGP, but not symmetrical, as juveniles succumbed to predation by adults one third of the time in

245 the absence of prey and in one of our replicates when prey were present. As IGP (e.g., Nilsson \&

246 Söderström 1988) and instances of cannibalism (e.g., Dending 1988, Hicks 1994, Yee, 2010)

247 exist among dytiscids, these interactions could further complicate the way in which changes in

248 predator life history may interact with prey, to perhaps change overall predation rates among life 249 history stages.

250 We did determine that the combined feeding of an adult and juvenile predator increased prey 251 consumption $30 \%$ over single predator stage trials. One explanation for this increased feeding is

252 due to predator spatial niches and foraging behavior. Adult L.f. rufus are active predators

253 (Pitcher \& Yee 2014) whereas L.f. rufus larvae are mostly sit-and-wait predators (personal 
254 observation); adults also move actively through the water column, whereas juveniles of this

255 species remain relatively motionless at the bottom or on plants. This suggests inherent spatial

256 differences among life history stages, and coupled with differences in how these predator stages

257 feed, may help to explain the synergistic effects with mixed versus single predator stages for

258 dytiscids. Such behavioral differences among dytiscid larvae in feeding mode and hunting

259 domain have been documented for larval dytiscids (Yee 2010), however this is the first study to

260 look at the potential role of larvae and adults to affect shared prey. One consequence of this work

261 is to suggest that there may be compounding effects upon prey populations in nature by predators

262 with complex life cycles (Wilbur 1980). To determine if this is the case, additional experiments,

263 wherein adult and juvenile predators of various densities are used, will need to be conducted.

264 Unintentionally, we also tested the effect of multiple predators of each prey stage. In

265 Experiment 1, single adult beetles ate more large prey but there were no differences between

266 prey sizes within beetle stage (Fig. 1), whereas in Experiment 2 when two adult predators were

267 tested they generally ate more early instars (predator effect combines data from adults and

268 juveniles, Fig. 2B). The experimental design was not identical between trials, however

269 differences in plant density and prey density that were investigated in Experiment 1 were non-

270 significant, and thus were eliminated in Experiment 2. Given this, differences in consumption

271 would seem to point to potential interactions between predators, an effect found in some other

272 studies. Aditya and Saha (2006), who tested predation of adults of the dytiscid Rhantus

273 sikkimensis at two different predator densities on mosquito and chironomid prey, noted

274 significant differences in prey consumed with two predators consuming more prey than three.

275 However, Chandra et al. (2008) found higher predation rates of two juvenile Acilius sulcatus

276 feeding on C. quinquefasciatus compared to one juvenile, although variation in prey 
277 consumption was also affected by prey density and volume. The interaction of multiple predators

278 on shared prey is understudied in aquatic insects in general, and dytiscids specifically, but as the

279 presence of multiple predators is the norm in natural temporary water bodies such data that

280 explores predator density are needed.

281 We also showed that adult L.f. rufus ate more dead mosquitoes compared to live ones. If

282 adult dytiscids are a good bio-control agent then we would expect living prey to be preferred

283 when given the choice between dead and living mosquitoes. Velasco and Millian (2008) found

284 that adult dytiscids chose to scavenge on dead animal material rather than to hunt living prey. A

285 similar result was observed by Kehl and Dettner (2003) who also tested prey preference by

286 giving the dytiscid Scarodytes halensis mixed treatments of dead and living plankton (Copepoda

287 and Cladocera). In our experiment, adult L.f. rufus had the ability to attack living prey when

288 given no choice, but attacked fewer living prey when dead prey were available. Scavenging on

289 dead animal material is common in dytiscids (Hicks 1994, Larson et al. 2000), and could be

290 favored if it requires lower energy expenditure. Scavengers (especially ones that are capable of

291 flight) can potentially transfer energy between adjacent ecosystems (Payne \& Moore 2006).

292 Considering the prevalence of this species in local water bodies (Pitcher \& Yee 2014), the rate at

293 which it scavenges, and potential mobility, this could possibly impact nutrient cycles in areas

294 that they inhabit, although such speculation requires more testing.

295 Our results showed that beetles of both stages caused a significant decrease in mosquito

296 densities, and support the results of others for dytiscids' ability to decrease mosquito larvae

297 populations (e.g., Formanowicz 1982, Culler \& Lamp 2009, Chandra et al., 2008). For example,

298 Chandra et al. (2008) observed that in a 24 hr period, juvenile Acilius sulcatus (Coleoptera:

299 Dytiscidae) ate on average 34 out of 200 late instar C. quinquefasciatus ( 17\%). The juvenile 
300 dytiscids used in our experiment consumed $28 \%$ of the late instar C. quinquefasciatus larvae

301 offered, even though the amount of time for this study's trials were shorter than those by

302 Chandra et al. (2008). It is still unclear the degree to which adult dytiscids or larvae are

303 important predators on mosquitoes in natural wetlands (Lundkvist et al. 2003, Shaalan and

304 Canyon 2009), however it is likely that they do represent an important predator under a variety

305 of circumstances, especially in fishless environments (Larson et al. 2000). Many different control

306 agents are utilized for population suppression of mosquito larvae including vertebrate predators

307 such as non-game fish (Kern 2004). In an experiment that tested prey preference of dytiscids and

308 mosquito fish it was observed that mosquito fish did not show a preference for mosquitoes,

309 however dytiscids did (Culler \& Lamp 2009). Compilation of knowledge surrounding different

310 species of dytiscids may allow researchers to construct better bio-control strategies that are more

311 efficient than single species approaches.

312 Plant density had no significant effect on consumption of mosquito prey. Different plant

313 densities were utilized because we predicted that higher plant densities would provide refugia for

314 prey. Elsewhere (Yee 2010), the presence of plants altered the behavior of larval dytiscids when

315 attacking their prey. One possible explanation for the lack of an effect of plants could be that the

316 plant stem densities used may not have been appropriate to allow prey to use as shelter or as a

317 vantage point for predators. Another explanation could be that Culex sp., including $C$.

318 quinquefasciatus, are open water dwellers and would not utilize plant refugia (Clements 1999).

319 Thus, even when offered plants as shelter, they may aggregate in the open water areas of the

320 habitat, where they would be vulnerable to predators. However, mosquitoes staying at the surface

321 regardless of plant density may also be a form of anti-predator behavior (Ohba \& Ushio 2015).

322 Such interactions between habitat factors, prey type, and predator life history and species in 
323 dytiscids have not been explored in detail.

324 We detected no significant relationship of prey density on consumption rates. Formanowicz

325 (1982), also did not find prey density to affect consumption rates across five different prey

326 densities for three different species of juvenile dytiscids. He also noted no difference between

327 predator searching times, handling time, and prey densities. In this case, it did not seem to matter

328 what density of prey that was administered, suggesting that the dytiscids take the same amount of

329 time to recognize, handle, and consume each prey. Additionally, Formanowicz (1982) attributed

330 his results to the many different ways that juvenile dytiscids can hunt for prey. For instance, at

331 low densities of prey juveniles would actively search at all times, whereas in high densities of

332 prey they utilized a sit and ambush tactic (Formanowicz 1982). Others have found that prey

333 density affects consumption of prey (Aditya \& Saha 2006), however explanations for why this

334 might occur are lacking.

335 It is clear that adult and juvenile L. f. rufus have different effects on a shared mosquito prey.

336 The compounding effect that both life stages of dytiscids may have on shared prey populations is

337 an underexplored area of research, but could be useful in understanding the degree to which

338 dytiscids serve, for instance, as biocontrols of mosquitoes in natural wetlands. Moreover,

339 research on intraguild predation would also be a necessary area of inquiry, where we hypothesize

340 that adult dytiscids would play the role top predator, the juvenile as the intermediate prey, and

341 the mosquito larvae as the basal resource. Our work points to an asymmetry in predation for

342 different life-history stages of L.f. rufus, an area that has not been identified previously. 
347 We thank S. Schelble, N.F. Ezeakacha, and W.C. Glasgow for assistance in the laboratory. This 348 work was supported by the Department of Biological Sciences at the University of Southern

349 Mississippi.

\section{Literature Cited}

Aditya G., Ash A. \& Saha G.K. 2006. Predatory activity of Rhantus sikkimensis and larvae of Toxorhynchites splendens on mosquito larvae in Darjeeling, India. Journal of Vector Borne

Aditya G. \& Saha G.K. 2006. Predation of the beetle Rhantus sikkimensis (Coleoptera: Himalayas of India. Limnologica 36: 251-257.

Alto, B.W., Malicoate J., Elliott S.M. \& Taylor J. 2012. Demographic consequences of predators on prey: trait and density mediated effects on mosquito larvae in containers. PLoS ONE 7: 1-

Batzer, D.P. \& Wissinger S.A. 1996. Ecology of insect communities in nontidal wetlands.

363 Annual Review of Ecology and Systematics 41: 75-100.

364 Bosi G. 2001. Abundance, diversity and seasonal succession of dytiscid and noterid beetles 365 Coleoptera: Adephaga. in two marshes of the Eastern Po Plain Italy. Hydrobiologia 459: 1-7.

366 Brogdon, W.G. \& McAllister J.C. 1998. Insecticide resistance and vector control. Emerging 367 Infectious Diseases 4: 605-613.

368 Chandra G., Mandal S., Ghosh A., Das D., Banerjee S. \& Chakraborty S. 2008. Biocontrol of 
larval mosquitoes by Acillus sulcatus (Coleoptera: Dytiscidae). BMC Infectious Diseases 8: 138-145.

371 Clements A.N. 1999. The Biology of Mosquitoes, vol. II. Chapman \& Hall, London, United $372 \quad$ Kingdom.

373 Culler L. \& Lamp W. 2009. Selective predation by larval Agabus (Coleoptera: Dytiscidae) on 374 mosquitoes: support for conservation- based mosquito suppression in constructed. Freshwater 375 Biology 54: 2003-2014.

376 Culler L., Ohba S. \& Crumrine P. 2014. Predator-prey interactions of dytiscids. In: Ecology, 377 Systematics, and the Natural History of Predaceous Diving Beetles (Coleoptera: Dytiscidae). 378 Ed. D.A. Yee, pp. 364-386, Springer, London.

379 Deding J. 1988. Gut content analysis of diving beetles (Coleoptera: Dytiscidae). Natura $380 \quad$ Jutlandica 22: 17-184.

381 Formanowicz D. 1982. Foraging tactics of larvae of Dytiscus verticalis Coleoptera: Dyticidae.: The assessment of prey sensity. Journal of Animal Ecology 51: 757-767.

383 Fretwell, S. D. 1987. Food-chain dynamics-the central theory of ecology. Oikos, 50, 291-301.

384 Hagen K., Bombosch S. \& McMurtry J.A 1976. The Biology and Impact of Predators. In:

385 Theory and Practice of Biological Control Ed. C.B. Huffaker, pp. 93-142, Academic Press, $386 \quad$ New York.

387 Hicks B. 1994. Foregut contents of adult Ilybius erichson Dytiscidae: Coleoptera. from 388 Newfoundland. Coleopterist Bulletin 48: 199-200.

389 Johnson J., Saenz D., Adams C.K. \& Connor R. 2003. The Influence of predator threat on the 390 timing and life-history switch point: predator-induced hatching in the southern leopard frog 391 (Rana sphenocephala). NRC Canada 81: 1608- 1613. 
Kern W.H. 2004. Some small native freshwater fish recommended for mosquito and midge control in ornamental ponds. ENY-670 Department of Entomology and Nematology, UF/IFAS Extension, pp. 1-4.

Klecka J. \& Boukal D. 2012. Who eats whom in a pool? A comparative study of prey selectivity by predatory aquatic insects. PLoS ONE 7: 1-13.

Kehl S. \& Dettner K. 2003. Predation by pioneer water beetles Coleoptera, Dytiscidae. from sand pit ponds, based on crop-content analysis and laboratory experiments. Archiv fur Hydrobiologie 1: 109-126.

Larson D. J., Alarie Y. \& Roughley R.E. 2000. Predaceous Diving Beetles Coleoptera: Dytiscidae. of the Nearctic Region. NCR Research Press, Ottawa.

Lundkvist E., Landin J., Jackson M. \& Svensson C. 2003. Diving beetles Dytiscidae. as predators of mosquito larvae Culicidae. in field experiment and in laboratory tests of prey preference. Bulletin of Entomological Research 93: 219-226.

McCoy M.W., Barfield M. \& Holt R.D. 2009. Predator shadows: complex life histories as generators of spatially patterned indirect interactions across ecosystems. Oikos 118: 87-100.

Nilsson A.N. \& Söderström O. 1988. Larval consumption rates, interspecific predation, and local guild composition of egg-overwintering Agabus (Coleoptera: Dytiscidae) species in vernal pools. Oecologia, 76, 131-137.

Ohba S. \& Ushio M. 2015. Effect of water depth on predation frequency by diving beetles on mosquito larvae prey. Entomological Science 18: 519-522.

Ohba S. 2009. Ontogenetic dietary shift in the larvae of Cybister japonicus Coleoptera: Dytiscidae. in Japanese rice fields. Environmental Entomology 38: 856-750.

Payne, L.X. \& Moore J. W. 2006. Mobile scavengers create hotspots of freshwater productivity. 
Oikos 115: 69-80.

416 Pitcher, K.A. \& Yee D.A. 2014. Habitat use, prey consumption, and dispersal responses as

417 potential coexistence mechanisms using two morphologically similar species of predaceous

418 diving beetles (Coleoptera: Dytiscidae). Annals of the Entomological Society of America

$419 \quad 107: 582-591$.

420 SAS Institute 2004. SAS/STAT users guide, version 6, 4th ed., vol. 1 and 2.

421 Savino J. \& Stein R. 2011. Predator-Prey interaction between largemouth bass and bluegills as

422 influenced by stimulated, submersed vegetation. Transactions of the American Fisheries

$423 \quad$ Society 3: 255-266.

424 Schmitz O. J. 2007. Predator diversity and trophic interactions. Ecology 88: 2415-2426.

425 Shaalan, A.-S. \& Canyon D.V. 2009. Aquatic insect predators and mosquito control. Tropical

$426 \quad$ Biomedicine 26: 223-261.

427 Thakare V.G. \& Zade V.S. 2011. Diversity, abundance and species composition of water beetles

428 Coleoptera: Dytiscidae, Hydrophilidae and Gyrinidae. in Kolkas Region of Melghat Tiger

429 Reserve, Central India. Academic Journal of Entomology 4: 64-71.

430 Velasco J. \& Millan, A. 2008. Feeding habits of two large insects from a desert stream: Abedus

431 herberti (Hemiptera: Belostomatidae) and Thermonectus marmoratus (Coleoptera:

432 Dytiscidae). Journal of Entomology 4: 64-71.

433 Vinogradova E, B. 2000. Culex pipiens pipiens mosquitoes: taxonomy, distribution, ecology,

434 physiology, genetic, applied importance and control. Sofia, Bulgaria. Pensoft publishers.

435 Wilbur H. 1980. Complex Life Cycles. Annual Review of Ecology and Systematics, 11, 67-93.

436 Yee D.A. 2010. Behavior and aquatic plants as factors affecting predation by three species of

437 larval predaceous diving beetles (Coleoptera: Dytiscidae). Hydrobiologia 637: 33-43. 
438 Young, A. M. 1967. Predation in larvae of Dytiscus marginalis Linneaus (Coleoptera:

439 Dytiscidae). Pan Pacific Entomology 43: 113.

440

441

442

443

444

445

446

447

448

449

450

451

452

453

454

455

456

457

458

459

460

461 
462 Table 1. Results of 4-way ANOVA showing effects of predator stage (juvenile, adult), prey

463 stage (early or late instar mosquito larvae), plant density (low, medium, high), and prey density

$464(5,10$, or 15 mosquito larvae) and all their interactions on consumption rates of mosquito prey.

465 Significant effects are presented in bold.

\begin{tabular}{llll} 
Factor & df & F & p-value \\
\hline Predator Stage (D) & 1,108 & 4.48 & $\mathbf{0 . 0 3 6 7}$ \\
Prey Stage (P) & 1,108 & 0.02 & 0.8835 \\
Plant Density (L) & 2,108 & 0.13 & 0.8823 \\
Prey Density (S) & 2,108 & 0.11 & 0.8919 \\
D x P & 1,108 & 9.48 & $\mathbf{0 . 0 0 2 6}$ \\
D x L & 2,108 & 0.13 & 0.8782 \\
D x S & 2,108 & 0.09 & 0.9163 \\
P x L & 2,108 & 0.24 & 0.7892 \\
P x S & 2,108 & 1.67 & 0.1926 \\
L x S & 4,108 & 0.39 & 0.8122 \\
D x P x L & 2,108 & 0.37 & 0.6898 \\
D x P x S & 2,108 & 0.08 & 0.9222 \\
D x L x S & 4,108 & 0.28 & 0.8895 \\
P x L x S & 4,108 & 0.29 & 0.8839 \\
D x P x L x & 6,108 & 0.08 & 0.9901 \\
\hline & & & \\
\hline & & & \\
& & &
\end{tabular}


468 Fig. 1 Results of the significant interaction between predator stages (juvenile and adult beetles) 469 and prey stages (early and late instar Culex quinquefasciatus) on mean ( $\pm \mathrm{SE})$ consumption rates.

470 Means that do not share a letter are significantly different based on mean separation with a 471 Tukey correction.

472 Fig. 2 Effects of single and combined predator life history stages on different stages of shared 473 prey, Culex quinquefasciatus. A) Significant effect of predator stage (2 juvenile, 2 adult, or 1 of 474 each Laccophilus fasciatus rufus) on mean $( \pm \mathrm{SE})$ percent consumption of larval Culex 475 quinquefasciatus. B) Significant prey stage effect for early $\left(1^{\text {st }}, 2^{\text {nd }}\right)$ and late $\left(3^{\text {rd }}, 4^{\text {th }}\right)$ instars of 476 prey offered either alone or in combination. In all panels means that do not share a letter are 477 significantly different based on mean separation with a Tukey correction.

478 Fig. 3 Results of a one-way ANOVA on mean ( \pm SE) consumption of mosquitoes by adult 479 dytiscids. Treatment levels included either 10 dead, 10 live, (noted as "10 prey" in the legend) or 480 a mixture of 5 living and 5 dead late instar mosquitoes (Culex quinquefasciatus). Means that do 481 not share a letter are significantly different based on mean separation with a Tukey correction. 482 


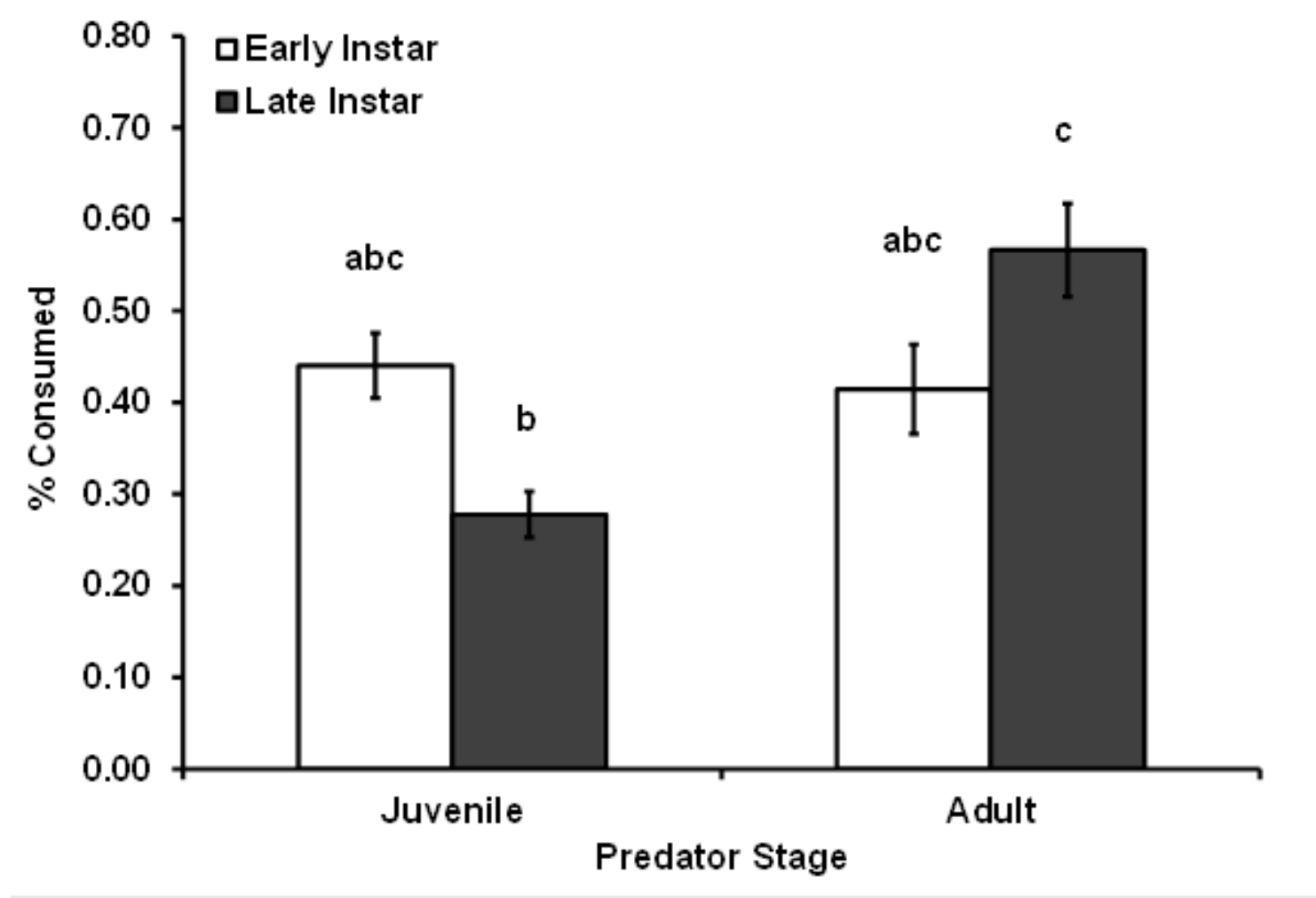

491

492

493

494

495

496

497

498

499

500

501 
502

503

504

505

506

507

508 Fig. 1

509

510

511

512 
A

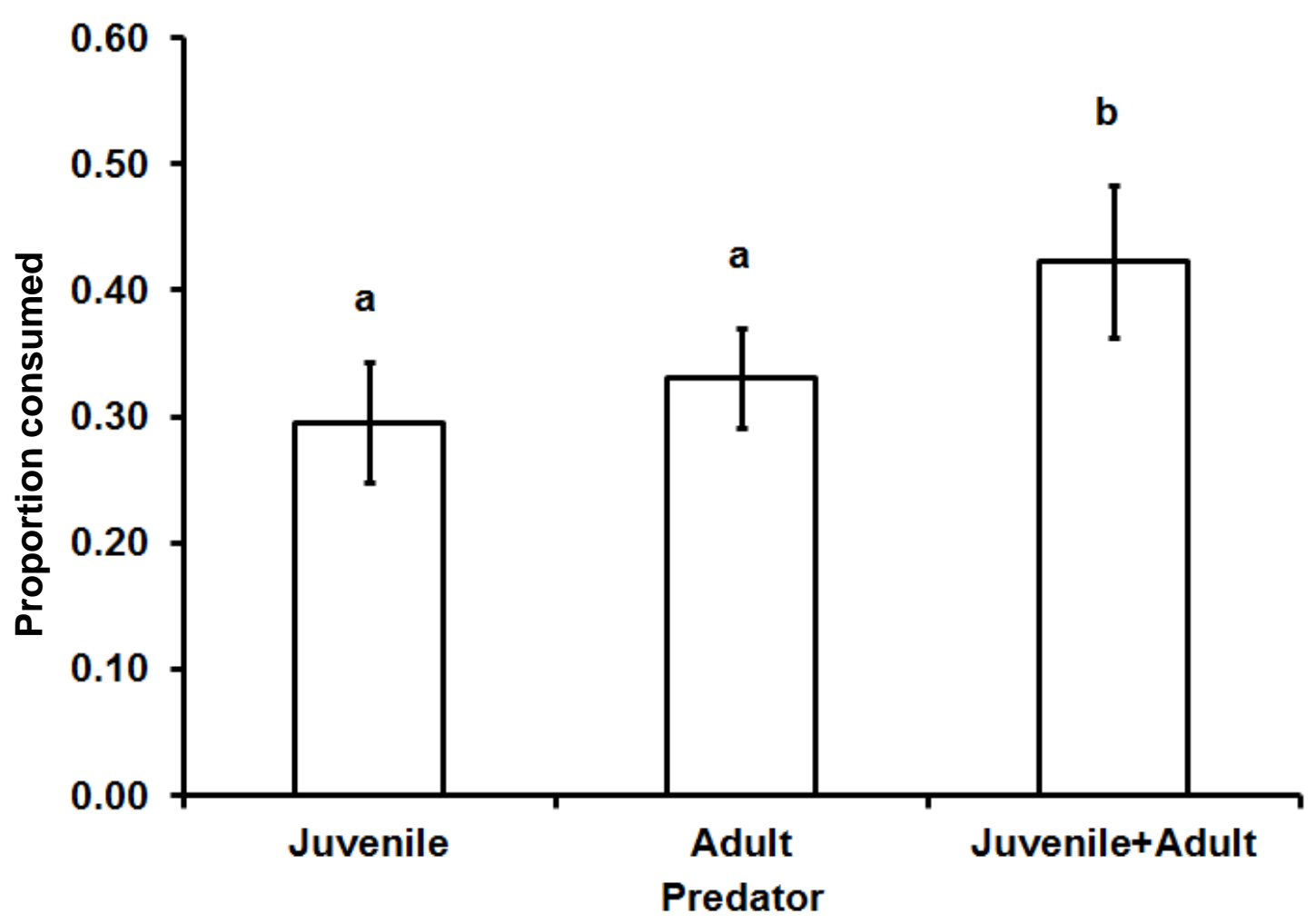

523

524

525

526

527

528

529

530

531

532

533

534

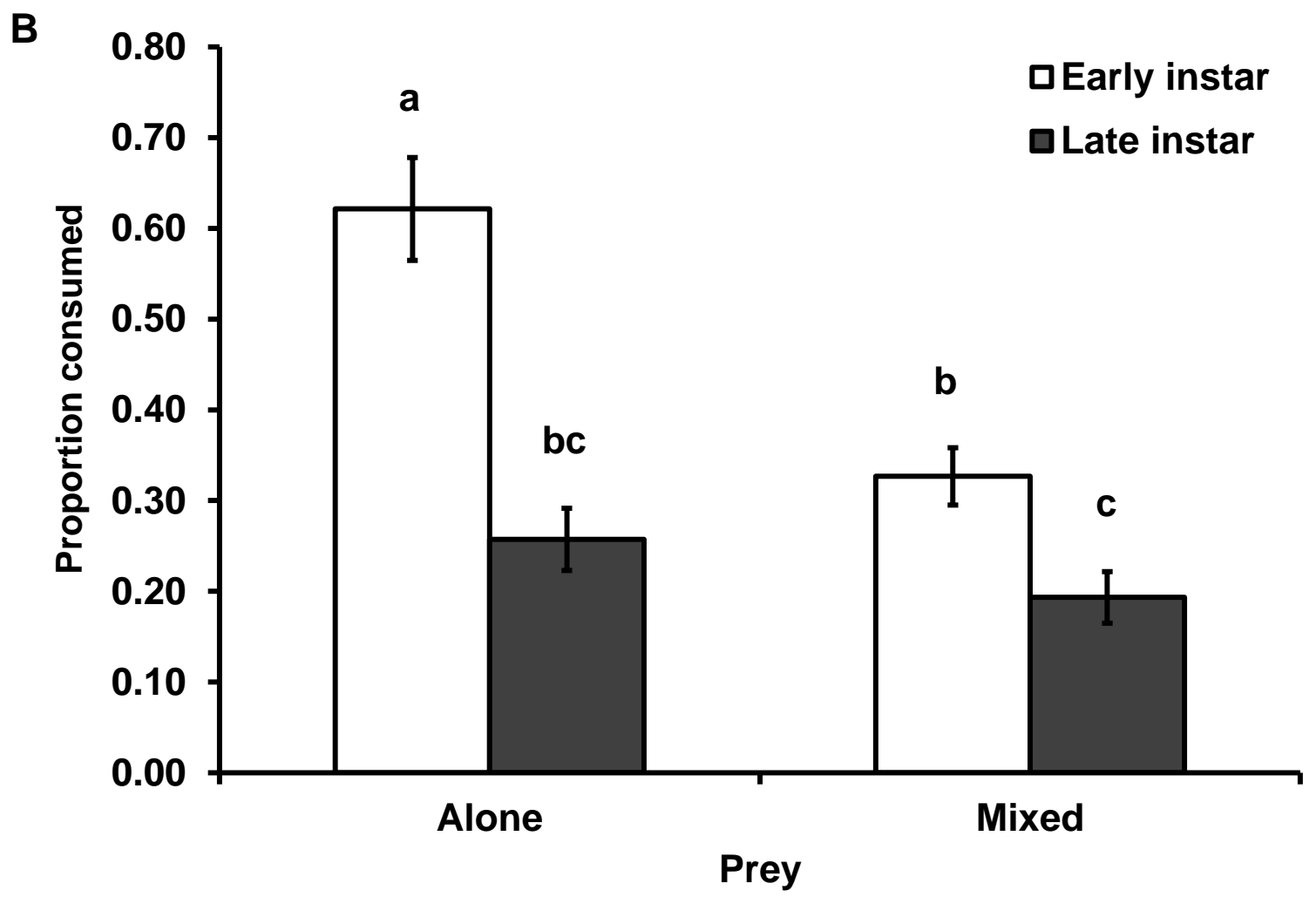

535 Fig. 2 
538

539

540

541

542

543

544

545

546

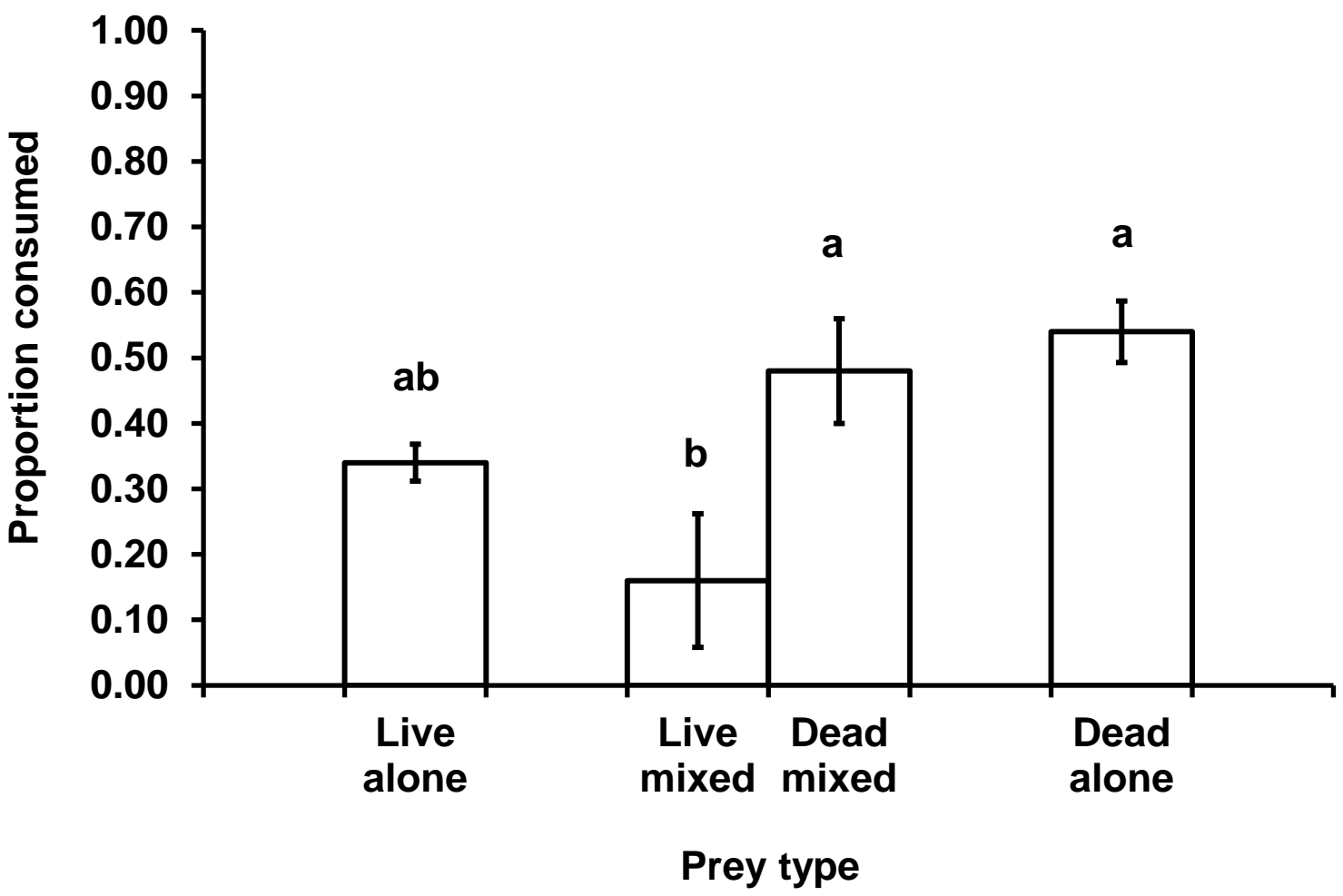

548

549

550

551

552 Fig. 3 